\title{
Utilidad de la tomografía computarizada en la sospecha de rotura cardíaca
}

\author{
Marcos Ferrández Escarabajal* \\ Alejandro Cruz-Utrilla** \\ Ana Bustos García de Castro*** \\ Patricia Mahía Casado* \\ * Servicio de Cardiología. Hospital Universitario Clínico San Carlos. Madrid. España \\ ** Servicio de Cardiología. Hospital Universitario Doce de Octubre. Madrid. España \\ ** Servicio de Radiología. Hospital Universitario Clínico San Carlos. Madrid. España \\ Recibido: 17/12/2019 \\ Aceptado: 07/01/2020 \\ En línea: :02/03/2020
}

Correspondencia

Marcos Ferrández Escarabajal marcos_ferres@hotmail.com

Citar como: Ferrández-Escarabajal M, Cruz-Utrilla A, Bustos-García de Castro A, Mahía-Casado P. Utilidad del TC en la sospecha de rotura cardíaca. Rev Ecocar Pract (RETIC). 2020 (Mar); 3 (1): 53-55. doi: 10.37615/retic.v3n1a14.

Cite this as: Ferrández-Escarabajal M, Cruz-Utrilla A, Bustos-García de Castro A, Mahía-Casado P. Usefulness of CT in cardiac ruptura suspiction. Rev Ecocar Pract (RETIC). 2020 (Mar); 3 (1): 53-55. doi: 10.37615/retic.v3n1a14

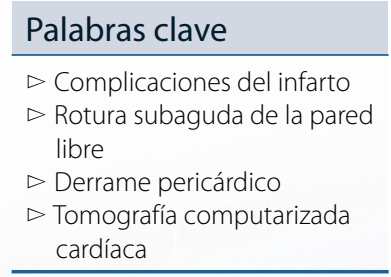

\begin{tabular}{l} 
Keywords \\
\hline$\triangleright$ Infarction complications \\
$\triangleright$ Subacute rupture of the free \\
$\quad$ wall \\
$\triangleright$ Pericardial effusion \\
$\triangleright$ Cardiac computed \\
$\quad$ tomography \\
\hline
\end{tabular}

\section{Presentación del caso}

Varón de 75 años, con antecedentes personales de diabetes mellitus tipo 2, hipertensión arterial y dislipidemia, que había tenido un ingreso hospitalario reciente en otro centro por síndrome coronario agudo sin elevación del ST (SCASEST), que fue manejado de forma conservadora sin realización de coronariografía diagnóstica. En la ecocardiografía al alta se describe un ventrículo izquierdo de tamaño y función sistólica normal, con movimiento septal anómalo en relación con trastorno de la conducción intraventricular. Como otros hallazgos relevantes se describía una estenosis aórtica moderada con insuficiencia ligera acompañante. En este ingreso también se comprobó que el paciente tenía un flutter auricular atípico, por lo que se inició tratamiento anticoagulante con edoxabán.

El paciente acudió al servicio de Urgencias del hospital de los autores al referir, desde el alta hospitalaria, aumento progresivo del perímetro de miembros inferiores acompañado de disnea progresiva. Puesto que el paciente tenía clínica miccional y en el urocultivo se aisló Staphylococcus aureus resistente a meticilina, se decidió ingresarlo para completar tratamiento antibiótico.
Ya en la planta de medicina interna, ante la presencia de clínica sugestiva de insuficiencia cardíaca se solicitó una nuevo ecocardiografía transtorácica. En el estudio se aprecia un derrame pericárdico severo parcialmente organizado y con tractos de fibrina (Vídeo 1 a Vídeo 4), sin datos de compromiso hemodinámico, salvo discretos signos de constricción. Al revisar con cuidado el ventrículo izquierdo se aprecia en el ápex un adelgazamiento muy marcado de la pared ventricular que podría corresponder a un pseudoaneurisma ventricular (Vídeo 5 y Vídeo 6). Con estos hallazgos se planteó la posibilidad de que el paciente tuviera una rotura subaguda de la pared libre ventricular, por lo que se solicitó una TC de tórax urgente.

En la TC se comprueba la presencia de un derrame pericárdico severo con espesor máximo de la pared de 4,2 cm sobre la cara lateral del ventrículo izquierdo y con una atenuación radiológica de 30-35 unidades Hounsfield, lo que sugiere abundante contenido proteico/hemorrágico. El miocardio y la grasa epicárdica tenían una estructura normal, lo que permitió descartar el pseudoaneurisma ventricular. Además, la adquisición de imágenes en fase tardía mostró un realce evidente del pericardio que aparece como una línea blanca tan perfectamente delimitada como si se hubiera pintado con un lápiz. Con estos hallazgos se llega al diagnóstico final de pericarditis postinfarto (Vídeo 7 y Figura 1). 
El paciente pasó a la unidad de cuidados agudos cardiovasculares, donde se realiza una ventana pericárdica que resulta parcialmente efectiva, con derrame pericárdico severo organizado persistente sobre todo en cara lateral del ventrículo izquierdo. Para completar estudio se realizó una coronariografía que no mostró estenosis coronarias significativas.

\section{Estudio por imagen}

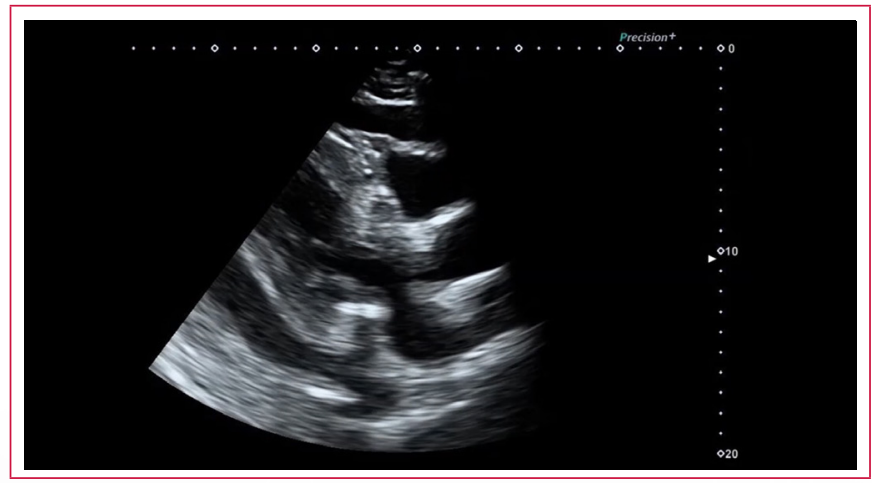

Vídeo 1. Plano paraesternal de eje largo. Destaca un derrame pericárdico circunferencial importante

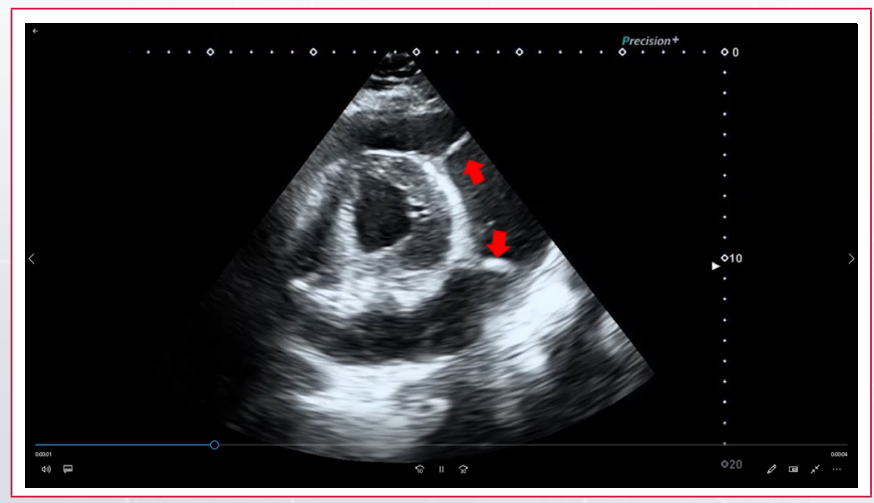

Vídeo 2. Plano paraesternal de eje corto. Se aprecia claramente que hay un derrame pericárdico severo, con bandas de aspecto denso (flechas) que atraviesan el derrame y corresponden a bandas de fibrina

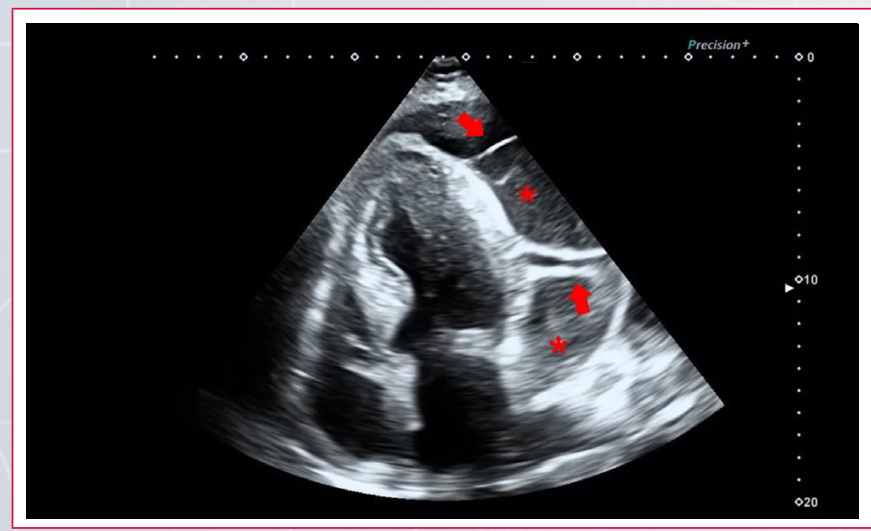

Vídeo 3. Plano apical de cuatro cámaras. De nuevo destaca el derrame pericárdico y las bandas de fibrina (flechas). El derrame tiene un aspecto heterogéneo con zonas densas que sugieren una estructura parcialmente organizada (asteriscos)

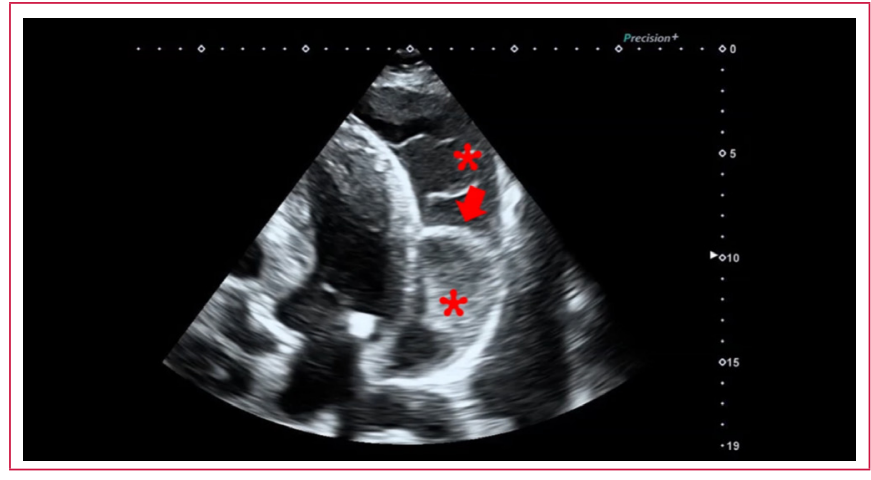

Vídeo 4. Plano apical de cuatro cámaras modificado para centrar la imagen en el derrame. De nuevo las bandas de fibrina (flechas) y las zonas de mayor densidad (asteriscos) son evidentes

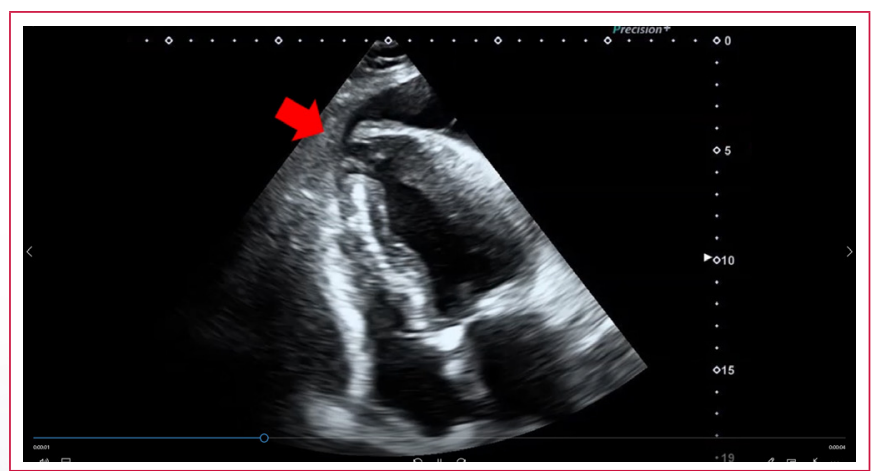

Vídeo 5. Plano apical de cuatro cámaras centrado en el ápex, donde se aprecia una zona de adelgazamiento y acinesia (flecha)

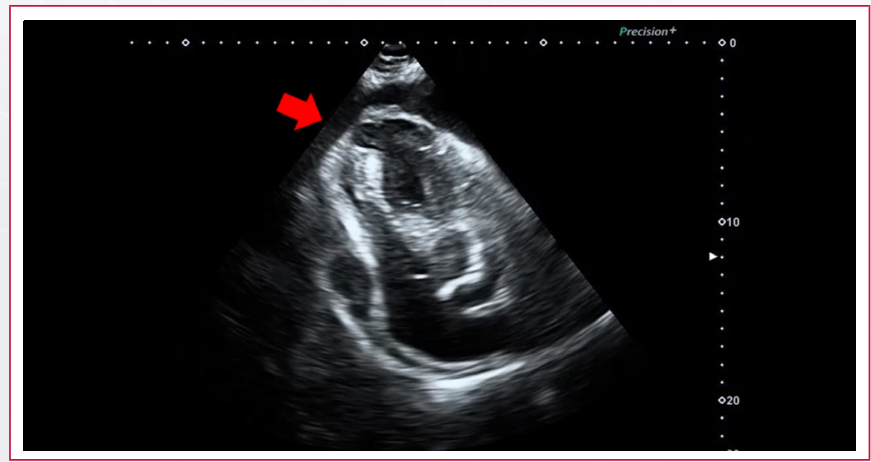

Vídeo 6. Forzando el plano se aprecia todavía de forma más evidente la acinesia y deformación apical

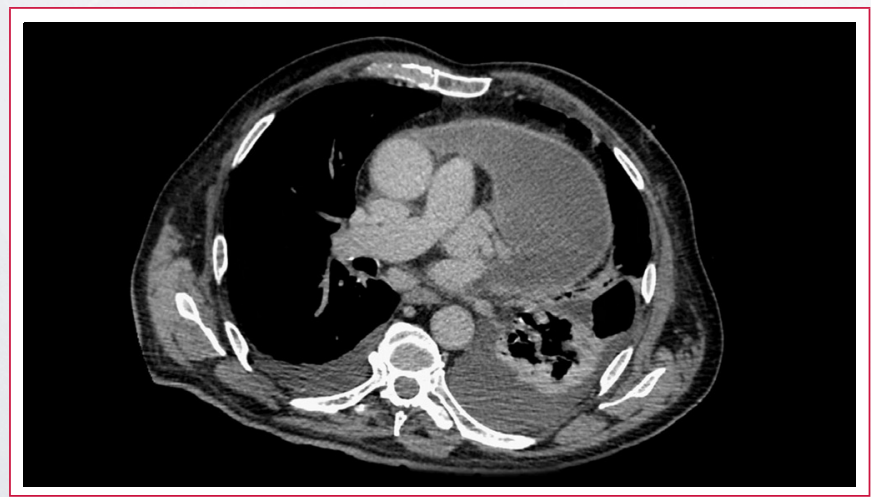

Vídeo 7. Estudio de TC cardíaca con sincronismo cardíaco y adquisición en fase venosa. Se aprecia un derrame pericárdico muy evidente y realce de yodo pericárdico lineal 


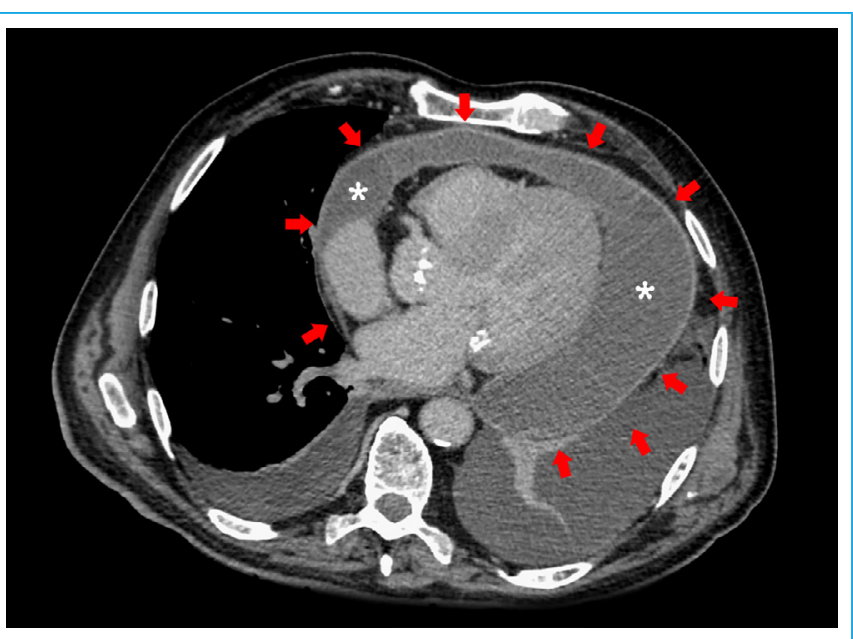

Figura 1. Detalle de la imagen de la TC. El derrame pericárdico es escandalosamente llamativo. Existe un realce de yodo lineal que dibuja el pericardio (flechas)

\section{Discusión}

Se trata de un caso en el que se sospecha una rotura subaguda de la pared libre ventricular ante la presencia de un derrame pericárdico severo de aspecto hemático con tractos de fibrina y una imagen sugerente de pseudoaneurisma apical en la ecocardiografía transtorácica en un paciente con síndrome coronario agudo reciente.

Aunque la TC cardíaca no es una prueba completamente admitida en las Guías de Práctica Clínica para valorar las posibles complicaciones mecánicas del infarto de miocardio, su amplia disponibilidad y la gran cantidad de información obtenida en la imagen hace que en su uso se esté haciendo cada vez más frecuente ${ }^{(1-3)}$. Este caso es un claro ejemplo de cómo la TC de tórax puede ayudar a descartar la presencia de rotura cardíaca contenida en un paciente con un alto grado de sospecha, puesto que permite valorar la estructura del miocardio. Además, la TC permite valorar también el líquido pericárdico, ya que una atenuación inferior a 10 unidades Housfield orienta a que el líquido tenga un bajo contenido proteico, mientras que un valor mayor de 10 sugiere que se trate de un líquido con abundante contenido proteico/hemorrágico. Finalmente, dado que el yodo de la TC se comporta de forma muy similar al gadolinio de la RM, la adquisición de imágenes en fase tardía permite valorar la presencia de realce de yodo en el pericardio, que es un marcador de inflamación activa. Finalmente, la TC de tórax ayuda a conocer el proceso subyacente causante del derrame pericárdico, y en pacientes con derrame pericárdico hemático la realización de una TC es especialmente importante, pues un porcentaje importante de los casos se debe a la presencia de una neoplasia activa.

En este caso clínico la presencia de realce pericárdico muy evidente sugiere inflamación activa. El paciente fue diagnosticado de pericarditis complicada con derrame pericárdico con transformación hemorrágica que se atribuyó al tratamiento con anticoagulantes de acción directa.

\section{Conclusión}

Aunque la ecocardiografía transtorácica es la técnica de imagen básica para valorar las posibles complicaciones del infarto de miocardio, la TC de tórax puede aportar información adicional muy importante para el diagnóstico y pronóstico, siempre y cuando se emplee en el contexto y la situación adecuados.

\section{Ideas para recordar}

- En un paciente con derrame pericárdico severo de aspecto hemático se deben descartar, en primer lugar, patologías que supongan un compromiso vital inmediato, como la rotura de pared libre ventricular tras el infarto o la rotura de una disección aórtica.

- La TC torácica es una prueba que puede ser útil en la valoración urgente de pacientes con sospecha de complicación mecánica del infarto.

- El contraste yodado de la TC se comporta de forma muy similar al gadolinio de la RM, por lo que se pueden realizar estudios de captación tardía que pueden ser muy útiles en casos complejos.

\section{Bibliografía}

1. Kligerman S. Imaging of Pericardial Disease. Radiologic Clinics of North America (2019); 57 (1): 179-199.

2. Figueras J, Barrabes JA, Serra V, et al. Hospital outcome of moderate to severe pericardial effusion complicating ST-elevation acute myocardial infarction. Circulation 2010; 122: 1902-1909.

3. LeWinter MM. Clinical practice. Acute pericarditis. N Engl J Med 2014; 371: 2410-2416. 